\title{
Intelectuais e imprensa: a configuração de uma rede hispano-americana no espaço atlântico
}

José Luis Bendicho BEIRED`

\begin{abstract}
Resumo: Este artigo trata da configuração de uma rede intelectual de dimensão internacional que uniu a América Latina e a Península Ibérica, a partir de meados do século XIX. Objetivamos analisar o papel dos intelectuais e órgãos de imprensa na formação dessa rede e discutir suas idéias e projetos, à luz do contexto político e do debate cultural. Consideramos que a ação dos intelectuais e da imprensa contribuiu para a configuração de um espaço singular de circulação de idéias e de formação de uma opinião pública iberoamericana.
\end{abstract}

Palavras-chave: Hispano-americanismo; Intelectuais; Imprensa.

A circulação de idéias e a convergência em torno de certos postulados de índole cultural e política no espaço atlântico conduziam à formação de uma comunidade intelectual de natureza singular que se auto-identificava como hispanoamericana. ${ }^{1}$ As idéias para a formação desta "comunidade imaginária" foram lançadas na década de 1830, mas apenas ganharam impulso a partir da metade do século XX, no contexto de afirmação das nacionalidades e de eclosão do sentimento nacionalista nas revoluções que varreram a Europa em 1848.

Esta tendência ocorreu paralelamente a certos processos de construção de identidades de âmbito internacional que se materializaram na emergência de movimentos de unificação, tais

- Professor do Departamento de História e do Programa de Pósgraduação em História - Faculdade de Ciências e Letras - UNESP Campus de Assis - 19806-900 - Assis - SP - Brasil. E-mail: jbbeired@assis.unesp.br.

HISTÓRIA, São Paulo, 28 (2): 2009

821 
como o pan-germanismo, o pan-eslavismo e o pan-latinismo. Dentre eles o pan-hispanismo mostrou-se uma força poderosa não só devido à pré-existência de elementos culturais comuns entre a América e a Península Ibérica, mas principalmente graças aos seus intelectuais, que assumiram um programa de aproximação entre os dois lados do Atlântico. ${ }^{2}$

Neste trabalho procuraremos examinar o papel desempenhado pelos intelectuais e pela imprensa na conformação de uma identidade supra-nacional de caráter hispano-americano, dando atenção especial à formação não apenas de um espaço de comunicação mas de uma rede que tinha nos jornais e revistas os seus veículos privilegiados. Com base nas pesquisas que realizamos sobre as relações culturais entre a Espanha e a América Latina, podemos afirmar que tais publicações foram elementos constitutivos de uma extensa rede mediante a qual tanto os seus editores quanto os autores veiculados faziam circular idéias e interagiam com outros agentes individuais e coletivos, em função de determinados interesses simbólicos e materiais. Esse processo circulação de idéias produzia efeitos variados que dependiam das condições de recepção dos leitores, ou seja, diferentes tipos de apropriação que por sua vez induziam à formulação de novas intervenções no campo da imprensa.

Em termos teóricos, pouca atenção foi dispensada pela historiografia latino-americana a certos problemas da história intelectual tal como tem sido trabalhada em anos recentes. Em especial a questão das condições de produção e de circulação das idéias, que no caso do hispano-americanismo apenas pode ser apreciado em escala internacional. Outro aspecto a ser considerado diz respeito à recepção dos autores e debates de um país sobre os outros, o que nos coloca o problema da apropriação e reelaboração das idéias formuladas em outros contextos. Por fim o estudo de um fenômeno que se desenvolveu em escala internacional leva-nos a inscrever esta reflexão nas vertentes que em anos recentes tem buscado compreender o problema das conexões entre diferentes espaços políticos, ou seja para além dos quadros nacionais. Essa ampliação do olhar 
INTELECTUAIS E IMPRENSA: A CONFIGURAÇÃO DE UMA REDE...

do historiador tem encontrado entusiastas entre autores tais como o indiano Sanjay Subrahmanyan e o francês Serge Gruzinsky que têm lançado mão do conceito de "historias conectadas"; por sua vez no campo da historia intelectual, Michel Espagne desenvolveu o conceito de "transferts culturels" visando analisar as conexões entre duas diferentes culturas nacionais e superar certos limites da história comparada. ${ }^{3}$

Que fenômenos concorreram para o estímulo do hispanoamericanismo? Primeiramente, o gradual arrefecimento do repúdio à Espanha depois das tensões experimentadas durante o processo de independência. A busca de aproximação das elites e do governo espanhol aos países americanos. A emigração da Península Ibérica que fomentou a formação de comunidades espanholas na América. Ao lado disso, a construção de um sentimento de oposição política e cultural aos Estados Unidos que se cruzava com uma afirmação da identidade latina em contraposição à anglo-saxã. Paralelamente, isso despertou a aproximação diplomática e cultural dos países da América Latina à Europa, principalmente da França e da Espanha.

A nossa hipótese é que a construção das identidades nacionais tornou-se um importante tópico do debate cultural latino-americano e espanhol que longe de restringir-se às fronteiras de cada país, foi presidido pelo intercâmbio de idéias e, portanto, também possui uma dimensão internacional freqüentemente ignorada pelas pesquisas. O desdobramento dessa hipótese é que se faz necessário equacionar o papel das relações políticas e culturais entre a América e a Espanha, pois consideramos que elas foram essenciais para a formação do "sentimento" de comunidade hispano-americana.

A partir de meados do século XIX, o projeto de fomentar a união das inteligências espanholas e americanas foi abraçado não apenas por inúmeras vontades individuais constituídas por intelectuais e figuram eminentes da vida publica, mas também por meio de empreendimentos coletivos integrados por intelectuais, empresários e políticos identificados com posições liberais, republicanas e democráticas. A criação de revistas e 
jornais foi um dos mais importantes meios, senão o principal, encontrado por tais projetos coletivos para a promoção da aproximação entre a Espanha e a América mediante uma ação que visava influenciar tanto a opinião pública quanto as forças políticas e os governos.

A quantidade de órgãos criados especificamente para essa causa é surpreendente. Só na Espanha podem ser elencadas diversas publicações: Revista de España, de Índias y del Exterior (1842- 1845); Revista Española de Ambos Mundos (1853 - 1855); La América. Crónica Hispano-Americana (1857-1886); El Museo Universal. Periódico de ciencias, literatura, artes, industria y conocimientos utiles (1857-169); El Imparcial. Revista hispanoamericana (1867-1870); La Ilustración Española y Americana (1869 - 1921); Revista hispanoamericana (1866 1872); La Integración Nacional (1870), que se transforma em Cuba Española; El Abolicionista (1865-1866); La Raza Latina. Periódico Internacional (1874-1884); El Correo de Espana. Periódico Internacional para la subregión no anglosajona del continente; Revista Crítica de Historia y Literatura Española, Portuguesa e Hispanoamericana (1895); e La UniónIberoAmericana (1886 - 1926) que na segunda fase passou a denominar-se Revista de las Españas (1926-1936).

Ao menos duas revistas do século XIX merecem menção. Primeiramente a Revista Española de Ambos Mundos, criada e dirigida pelo diplomata uruguaio Alejandro Magariños Cervantes, sob a inspiração da Revue de Deux Mondes. Publicada simultaneamente em Madri e Paris, teve uma vida breve, mas importante em vista do seu caráter pioneiro e por lançar as bases de um modelo que será seguido por outras revistas posteriormente. Com uma orientação política liberal, a revista reuniu em torno alguns dos mais importantes intelectuais espanhóis e latino-americanos em torno do ideal da união hispânica. Os objetivos da publicação foram claramente expostos por Magariños Cervantes no seu primeiro número: 
INTELECTUAIS E IMPRENSA: A CONFIGURAÇÃO DE UMA REDE...

Destinada a España y América pondremos particular esmero en estrechar sus relaciones (...). Felizmente han desaparecido las causas que nos llevaron a la arena del combate, y hou el pueblo americano y el ibero no son ni deben ser más que miembros de uma misma familia, la gran família española (...). La Revista consagrará artículos especiales al examen y solución de varias cuestiones em que están empeñados el porvenir y los más caros intereses de Espana y América (...). Los interesse de América y el arte americano ocuparán por primera vez en Europa y en una publicación especial la supremacia y el lugar que les corresponde (...). ${ }^{4}$

Depois de funcionar por dois anos, o lugar da Revista Española de Ambos Mundos foi ocupado pela revista La América. Crónica Hispano-Americana, que foi a mais prestigiosa e longeva publicação espanhola que se bateu pelo hispano-americanismo no século XIX. Fundada e dirigida pelo jornalista catalão Eduardo Asquerino, teve um forte apoio financeiro da burguesia comercial de Cádiz e deu continuidade ao projeto de sua antecessora, da qual incorporou muitos dos colaboradores. Como porta-voz do chamado partido progressista-democrático, que se identificava com o regime republicano (tinha nos seus quadros Emílio Castelar, Francisco Pi y Margall, entre outros), publicou autores dos mais importantes dos dois lados do Atlântico.

Vale salientar que a revista identificava-se com o projeto dos republicanos progressistas espanhóis de realização da União Ibérica, ou seja a unificação de Portugal e Espanha sob a forma federativa. A rigor essa era uma idéia antiga compartilhada por intelectuais portugueses e espanhóis, retomada com maior vigor a partir de meados do XIX sob o influxo das idéias de unificação alemã e italiana. Para tanto, quatrocentos espanhóis e portugueses reuniam-se em Paris durante as jornadas da Revolução de 1848 e fundavam o Club Ibérico em favor da união peninsular. Do lado português tal idéia foi impulsionada por figuras tais como o romancista Almeida Garret e o historiador Oliveira Martins enquanto do lado espanhol por figuras tais como Pi y Margall, Rafael Maria de 
Labra, Emilio Castelar por meio de uma série de jornais, revistas, livros e panfletos (ÁLVAREZ JUNTO: 2005, 524-531). Em suma, havia entre tais intelectuais a tese de que a afirmação da Espanha e Portugal no concerto europeu passava não só pela união ibérica, mas também pela formação de uma grande confederação ibérico-americana.

A revista notabilizou-se pela defesa da identidade cultural e de interesses políticos e materiais entre a Península Ibérica e a América Latina, ao lado da oposição desta em relação aos Estados Unidos. Diversos artigos foram publicados nessa direção, incluindo textos do dominicano Francisco Muñoz del Monte e do colombiano José Maria Samper originalmente editados pela Revista Española de Ambos Mundos. Muñoz del Monte assinalava a rivalidade da "raça latina" em relação às "raças anglo-germânicas", ao passo que José Maria Samper acentuava que o conflito entre duas formas de civilização (VAN AKEN, 1959, 72; LOPEZ-OPCON: 1987, P. 167).

Adepta de reformas do regime colonial espanhol, La América também abriu suas páginas para a publicação de textos dos defensores da abolição da escravidão em Cuba e Porto Rico, assim como recebeu diversas colaborações do cubano José Marti durante a sua estadia como deportado na Espanha e nos Estados Unidos. Durante o primeiro semestre de 1881 a revista promoveu uma campanha pelo fim da monarquia na Espanha e pela abolição da escravidão em Cuba. Informava, por exemplo, a participação de Joaquim Nabuco em uma manifestação pública contra a escravidão realizada em Madrid em janeiro daquele $a^{5}{ }^{5}$. Os dados sobre sua tiragem são incompletos, mas tudo indica que possuía uma difusão muito expressiva. Na Espanha, as províncias (menos Madri) chegaram a ter 12.000 assinantes e na América, só as Antilhas tiveram 21.750, na sua maioria residentes em $\mathrm{Cuba}^{6}$.

A tais publicações somavam-se aquelas produzidas na América pelas comunidades de imigrantes espanhóis. Em meados da década de 1870, uma onda de imigrantes de peculiar perfil dirigiu-se à América em função da derrocada da Primeira República em $1874^{7}$. Tais imigrantes eram militantes e políticos 
INTELECTUAIS E IMPRENSA: A CONFIGURAÇÃO DE UMA REDE...

que exerciam ofícios de jornalistas, escritores, editores, livreiros, ilustradores, artistas, impressores, enfim personagens pertencentes ao mundo intelectual e cultural que foram perseguidos pela restauração monárquica em função de suas posições republicanas. Em sua maioria opositores à monarquia, eram defensores do regime republicano de variada coloração ideológica: liberal, democrática, socialista, anarquista e maçônica. A Argentina foi o país escolhido pela maioria desses personagens, os quais uma vez estabelecidos contribuíram sob diversas formas para o incremento da vida cultural do país. Fundaram revistas, editoras e entidades culturais, assim como participaram vivamente de importantes empreendimentos jornalísticos, tanto de perfil comercial quanto político ${ }^{8}$. Dentre os jornais criados, destacou-se El Correo Español (1872) que desde Buenos Aires tornou-se o principal porta-voz da coletividade espanhola na Argentina e do estreitamento de laços com a Espanha, tendo sobrevivido até a década de 1940, sob o nome de El Diário Español. Dentre as revistas destacou-se España (1903), que passou a denominar-se Hispania em 1911. Mantida até 1951 pela Associação Patriótica Espanhola de Buenos Aires, a revista possuía uma política editorial que incluía um rol de importantes intelectuais espanhóis que trabalhavam como colaboradores permanentes.

$\mathrm{Na}$ última década do século XIX ganhou impulso o estreitamento de laços culturais e políticos entre a Espanha e a América em função das circunstâncias internacionais. A guerra Hispano-Americana colocara em campos opostos não só a Espanha e os Estados Unidos, mas também a maioria dos países hispano-americanos contra a ameaça do expansionismo norteamericano. A derrota da Espanha e a tutela sobre Cuba e Porto Rico representaram uma grande ofensa que uniu o mundo hispano-americano em torno de um clamor que teve no escritor Ruben Dario o seu maior intérprete por meio do artigo El triunfo de Caliban, publicado em 1898 no jornal El Tiempo de Buenos Aires e na revista $E l$ Cojo Ilustrado, de Caracas.

A América Latina se fez crescentemente presente na opinião pública e no ambiente intelectual espanhol por meio da HISTÓRIA, São Paulo, 28 (2): 2009 
JOSÉ LUIS BENDICHO BEIRED

difusão crescente de livros e matérias sobre a região, vista como dinâmica, aberta às possibilidades do futuro e destino para os emigrantes espanhóis. Para os intelectuais espanhóis, as relações entre a Espanha e a América teriam uma ação regeneradora sobre a realidade peninsular vista como mergulhada num quadro desolador de atraso e decadência. Dessa forma, os intelectuais americanos passaram a ter uma maior presença na imprensa e no mercado editorial espanhóis, e justamente a partir dessa posição projetaram-se não só em relação a outros países da Europa, mas sobretudo em relação à própria América, ganhando uma divulgação muito maior do que aquela que poderia ser obtida simplesmente em seus países de origem. Vários desses autores americanos passaram a viver na Espanha durante parte de suas vidas, onde participaram intensamente da vida pública e intelectual, num processo que o crítico Pedro Henríquez Ureña denominou como "transplante". Dentre os intelectuais transplantados figuraram desde personagens que se integraram ao sistema político espanhol, como o cubano Rafael Maria de Labra, vinculado ao Partido Liberal e fundador da Institucion Libre de Enseñaza ${ }^{9}$, ou ao campo literário, a exemplo do nicaraguense Ruben Dario e dos mexicanos Francisco Antonio de Icaza e Alfonso Reyes, até figuras que mantiveram posições críticas tais como os cubanos José Marti e Paul Lafargue, anarquista e genro de Karl Marx ${ }^{10}$.

Paralelamente à difusão dos intelectuais americanos pela grande imprensa espanhola, os autores espanhóis também passaram a ser amplamente difundidos na imprensa da América Hispânica. Diversos autores fizeram parte do quadro de articulistas de diversos jornais e revistas de grande circulação a exemplo Emilio Castelar, Perez Galdós, Francisco Pi y Margall, Juan Valera, Miguel de Unamuno e José Ortega y Gasset, entre muitos outros ${ }^{11}$.

Vale destacar o papel desempenhado por algumas publicações de espírito hispano-americanista voltadas para o público intelectualizado que se notabilizaram pela ampla irradiação geográfica na América Latina e na Península Ibérica, incluindo o Brasil e Portugal. Uma delas é a revista da 
INTELECTUAIS E IMPRENSA: A CONFIGURAÇÃO DE UMA REDE...

associação Unión Ibero-Americana, que se distinguiu por divulgar noticias da vida cultural e a publicação de autores tanto de primeira grandeza quanto menos conhecidos, contribuindo para organizar uma comunidade intelectual de caráter internacional por cinco décadas até o final da revista em 1936. A publicação desempenhou um relevante papel no sentido de promover o hispano-americanismo entre autoridades políticas, intelectuais, empresários, jornalistas, enfim aos setores dirigentes dos países ibero-americanos. A preocupação com a difusão da revista era constante. Em 1910, um anúncio sobre assinaturas da publicação informava: "Es la revista española de mayor circulación en la América Latina"12. Por sua vez, a memória das atividades de 1914 noticiava o envio de 10.000 exemplares à América ${ }^{13}$. Essa preocupação também se refletia na divulgação dos pontos de venda, que na Espanha eram 27 e na América Latina chegavam a 195, em 1928, concentrados no México (17), Peru (15) e Argentina (14), seguidos pelo Brasil (10), Colômbia (8) e Uruguai (80). Não menos relevantes são as informações oferecidas pela revista sobre o recebimento de jornais, revistas e boletins do exterior, boa parte deles mediante permuta. Como exemplo, em 1909, foram recebidos da América Latina 322 diferentes títulos de jornais diários, 126 títulos de revistas e 23 de boletins, os quais, contando cada um com vários exemplares, perfaziam um conjunto que alcançava a casa dos milhares. Nesse ano, a associação também informava que havia recebido um total de 22.993 exemplares de jornais e 4.009 de revistas, incluindo as publicações espanholas, conjunto de materiais que eram ano a ano incorporados ao acervo da biblioteca da associação. ${ }^{14}$ Tais números exemplificam a importância conferida aos órgãos de comunicação para o desenvolvimento da campanha unionista dessa associação e o alcance efetivo conquistado por uma publicação que efetivamente conseguiu manter de forma contínua por cinqüenta e um anos como foro de comunicação entre a Espanha e a América.

Outra é a revista La Gazeta Literária, fundada em 1926 por Ernesto Gimenez Caballero. Em 1927 foi publicado um artigo 
JOSÉ LUIS BENDICHO BEIRED

intitulado "Madri, meridiano intelectual de América Hispânica", de autoria do secretário de redação, Guillermo de Torre, conhecido escritor vanguardista que desatou uma onda de polêmicas envolvendo autores e revistas dos dois lados do Atlântico. Com esse texto-manifesto, Guillermo de Torre propunha a eliminação do termo América Latina e os seus neologismos do vocabulário da língua espanhola por considerálos espúrios. Aceita-los equivaleria ser cúmplice das "obscuras manobras anexionistas das França e da Itália" em relação à América, pois na política latinista desses países, a Espanha e outros expoentes ficavam á margem, ou desempenhando um papel confuso e secundário. "Diante da atração desviada de Paris, assinalemos Madri , em nossa geografia espiritual, como o ponto meridiano mais exato, como amais autentica ,linha de intersecção entre a América e a Espanha. Madri - ponto convergente do hispano-americanismo equilibrado, não limitador, não coativo, generoso e europeu - em contraposição a Paris - reduto do latinismo estrito, parcial, desdenhoso de tudo que não gire em torno do seu eixo" (TORRE: 1995, 521- 523). Rapidamente essa posição que traduzia a visão dominante no ambiente intelectual espanhol produziu respostas contundentes. A primeira, do jornal literário portenho Martin Fierro, que publicou uma resposta assinada por diversos escritores, dentre eles Jorge Luis Borges, desdenhado das pretensões de tutela intelectual espanhola. Fez-se acompanhar de outras respostas, também por meio da imprensa, como a do uruguaio Zum Felde, ao lembrar que os americanos havia tempos estabeleciam relações diretas com a Europa sem a necessidade de passar pelas alfândegas dos Pirineus ${ }^{15}$. E do Peru, José Carlos Mariátegui discutia a batalha travada por Martin Fierro, em defesa da autonomia intelectual da América Hispânica e sugeria que se um meridiano intelectual equivalia a mercado literário, ele passava pelo continente americano, principalmente por Buenos Aires e o México. ${ }^{16}$

Por sua vez o diário madrilenho El Sol foi um outro agente coletivo empenhado no estreitamento de laços mediante uma explicita valorização dos assuntos americanos. Expressão de um 
INTELECTUAIS E IMPRENSA: A CONFIGURAÇÃO DE UMA REDE...

projeto liberal que contou com José Ortega y Gasset entre os seus idealizadores, o jornal visou os setores mais influentes e intelectualizados da opinião publica com o objetivo de contribuir para a regeneração e a modernização da vida política e cultural espanhola. A atenção dispensada à América hispânica e em especial à Argentina, pode ser aquilatada em matéria de primeira página em 1923, sobre o banquete oferecido em homenagem de Luis Mitre, presidente do Conselho de Administração do portenho La Nacion, pelos colaboradores espanhóis do diário argentino, contando com a presença de ministros e do proprietário do diário $E l S^{S o l}{ }^{17}$. O jornal é uma interessante fonte da visão espanhola da América entre 1917 e o início dos anos 30 em função dos temas, análises, polêmicas, representações e autores publicados. As relações culturais entre a Espanha e a América eram privilegiadas, discutindo-se, por exemplo: o papel do jornal El Sol na competição pela influencia sobre a opinião pública hispano-americana; o problema da propriedade literária e cultural hispano-americana; a resenha de livros hispano-americanos e comentários sobre a vida cultural da América hispânica; a critica à expressão América Latina e à política latinista francesa; critica a setores portugueses que almejavam uma aliança entre Portugal-Brasil e França; a Espanha e a América na Sociedade das Nações; o problema da difusão do livro espanhol na América; as condições dos emigrados na América; as relações entre os Estados Unidos e o restante da América.

Dentre as polêmicas levantadas, uma chama a atenção, a partir da publicação de uma carta enviada ao jornal pelo argentino Leopoldo Lugones, em $1925^{18}$. Na carta, esse escritor criticava a viabilidade de um "congresso livre de trabalhadores intelectuais" hispano-americanos sugerido por um publicista peruano, por considerar vazio o conceito de "pensamento hispano-americano". Conhecido por seu nacionalismo, em seus argumentos o escritor afirmava faltar unidade entre os países da região e assinalava a forte influencia dos Estados Unidos em diversos aspectos da vida dos países a exemplo da Argentina, citando a justiça federal, as escolas normais, o sistema 
monetário, o comércio internacional e até o funcionamento da indústria e dos fogões de cozinha, movidos a carvão norteamericano. Como era de se esperar, as considerações provocaram as mais fortes reações contra o anti-hispanismo de Lugones e as mestiçagens culturais em curso na Argentina que distorciam o legado espanhol na América, a exemplo do "lunfardismo" 19 na Argentina pela corrupção que produzia sobre a língua espanhola ${ }^{20}$.

Tomamos aqui apenas alguns exemplos de publicações, sobretudo espanholas, que tiveram papel significativo na promoção do debate intelectual hispano-americano. É uma opção metodológica para a aproximação a uma problemática que ainda merece aprofundamento e que não ignora a importância de outros órgãos publicados na América Latina que também contribuíram para a formação de uma rede intelectual de escala internacional. Certamente também foram importantes revistas como a costa-riquenha Repertório Americano, a argentina Sur e a mexicana Cuadernos Americanos.

O desenvolvimento de uma identidade hispano-americana teve os intelectuais como agentes fundamentais em função das suas intervenções no prol do restabelecimento de laços entre ibéricos e americanos. Diversos foram os instrumentos mobilizados - publicações, criação de associações, iniciativas governamentais, organização de congressos - mas dentre todos, acreditamos que a imprensa foi um dos principais para o seu desenvolvimento. $O$ surgimento de inúmeros meios de inúmeros jornais e revistas na segunda metade do século XIX em diante e a sua circulação entre a Península Ibérica e a América Latina, permitiu conferir uma visibilidade internacional aos intelectuais e uma amplificação inédita dos debates políticos e culturais. Dessa maneira, portanto, tomou forma toda uma agenda de problemas e enfoques que para além das fronteiras nacionais, passaram a ter uma dimensão atlântica. Como vimos, as propostas e abordagens nem sempre foram consensuais, mas foi significativa a força de uma rede que interligou figuras da vida intelectual dispostas em diferentes países e que permitiu a 
INTELECTUAIS E IMPRENSA: A CONFIGURAÇÃO DE UMA REDE...

configuração de um espaço singular de circulação de idéias e de formação de uma opinião pública ibero-americana.

\section{Referências Bibliográficas}

ÁLVAREZ JUNTO, José. Mater Dolorosa. La idea de EspaÑa en el siglo XIX. Madrid: Taurus, 2005.

BIAGINI, Hugo. Intelectuales y políticos españoles a comienzos de la imigración masiva. Buenos Aires: CEAL, 1995.

ESPAGNE, Michel. Les transferts culturels franco-allemands. Paris: PUF, 1999.

LOPEZ-OCON, LEONCIO. Biografia de "La América". Una crónica hispano-americana del liberalismo democrático español. (18571886). Madri: CSIC, 1987,

PRADO, Maria Ligia Coelho. "Repensando a história comparada da América Latina". Revista de História, São Paulo: USP, 2005, n 153, p. $11-33$.

RAMA, Carlos. Historia de las relaciones culturales entre Espanha e América Latina. Siglo XIX. México, D.F.: F.C. E., 1982.

SCHWARTZ, Jorge (org.). Vanguardas latino-americanas. Polêmicas, manifestos e textos críticos. São Paulo: Edusp; Iluminuras, 1995.

VAN AKEN, Mark. Pan-hispanism. Its origin and development to 1866. Berkeley: University of California Press, 1959.

BEIRED, José Luis Bendicho. Intellectuals and press: the configuration of an Hispanic-American network in the Atlantic space. História, v.28, n.2, p.821-836, 2009.

Abstract: This article deals with the development of an intellectual network of international dimension that joined 
JOSÉ LUIS BENDICHO BEIRED

Latin America and Iberian Peninsula, from mid-nineteenth century. We aimed to analyze the role of intellectuals and the media in the formation of this network and discuss their ideas and political projects, in the light of the political and cultural debate. We consider that the action of intellectuals and the press contributed to the setting of a singular espace of circulation of ideas and the formation of Ibero-American public opinion.

Keywords: Hispano-americanism; Intellectuals; Press.

\section{NOTAS}

1 Trabalho apresentado no XXV Simpósio Nacional de História da Anpuh, Fortaleza, 2009. A pesquisa foi realizada com o apoio financeiro da FAPESP e do CNPq.

$2 \mathrm{O}$ pan-hispanismo conviveu com e frequentemente incluiu $\mathrm{O}$ iberismo, isto é, o ideal de união de Espanha e Portugal, defendido principalmente por republicanos de ambos os países. Em meio às barricadas de 1848, quatrocentos espanhóis e portugueses reuniram-se em Paris e fundaram o Club Ibérico em favor da união peninsular. Do lado português tal idéia foi impulsionada por figuras tais como o romancista Almeida Garret e o historiador Oliveira Martins enquanto do lado espanhol por figuras tais como Emilio Castelar, Francisco Pi y Margall e Rafael Maria de Labra por meio de uma série de jornais, revistas, livros e panfletos

${ }^{3}$ Sobre a relação entre a história comparada e a proposta das "histórias conectadas" ver PRADO: 2005, 11-33. Sobre o conceito de transferências culturais, ver ESPAGNE: 1999. 
INTELECTUAIS E IMPRENSA: A CONFIGURAÇÃO DE UMA REDE...

4 MARAGIÑOS CERVANTES, Alejandro, A. "Objetivos", Revista Española de Ambos Mundos, n. I, 1857, apud LÓPEZ-OCON: 1987, 73.

${ }^{5}$ LOPEZ-OCON, L. Op. Cit., p. 155.

${ }^{6}$ Dados para o período entre 1860-1863 levantados pela pesquisa de LOPEZ-OCON, L.: 1987, 118-119.

${ }^{7}$ De vida efêmera, durou entre 1873 e 1874.

${ }^{8}$ O espanhol Estebán Gimenez foi co-fundador com o argentino Juan B. Justo do jornal socialista La Vanguardia e redator do programa que deu origem ao Partido Socialista; por sua vez $\mathrm{La}$ Protesta, principal órgão do anarquismo da Argentina, foi fundado e dirigido inicialmente por anarquistas catalães. Das publicações comerciais, destacou-se a participação no jornal La Nación e em revistas ilustradas tais como don Quijote, Caras y Caretas, PBT, El cid Campeador, Fray Mocho e Plus Ultra, ademais da contribuição editorial na área educacional, com a criação da revista La Escuela Primaria, pelo pedagogo espanhol Enrique de Santa Olalla que ficou conhecido como o "patriarca da pedagogia argentina". ( BIAGINI: 1995, 13-4)

${ }^{9}$ Labra também foi o reitor dessa instituição que funcionava como uma universidade aberta.

10 Cf. "Los trasplantados latinoamericanos em Espana" in RAMA:1982, $258-272$.

11 "Los emigrados" in RAMA: 1982, $274-284$.

${ }^{12}$ Ubión Ibero-Americana, 31/03/1910, p. 30.

13 Esse número foi relatado na memória correspondente às atividades de 1914, por ocasião do número comemorativo da Festa da Raça, efeméride celebrada no dia 12 de outubro de cada ano. Unió Ibero-Americana, 31/01/1915, p. 30.

14 "Memória correspondiente a 1909". Unión Iber-Americana, 28/02/1910, n 2 , p. 22.

${ }^{15}$ Publicado em La Pluma, 1 (agosto de 1927). Apud SCHWARTZ: 1995, 524.

16 Publicado em Variedades (Lima), de 24/09/1927. Apud SCHWARTZ: 1995, 526.

${ }^{17}$ El Sol, 26/04/1923. 
18 LUGONES, Leopoldo. "Un congreso libre de trabajadores intelectuales". In El Sol, 16/04/1925.

${ }^{19}$ Nome conferido ao conjunto de termos de uso coloquial criados e empregados pelos setores populares de Buenos Aires.

20 PEREZ, Dionísio. "El lunfardismo en Sudamérica". In Sol, 21/04/1925; OLARIAGA, Luis. "No se puede hacer patria olvidando la raza". In Sol, 28/04/1925.

Artigo recebido em 07/2009. Aprovado em 11/2009. 